\title{
THE ROLE OF DESTINATION SPATIAL SPILLOVERS AND TECHNOLOGICAL INTENSITY IN THE LOCATION OF MANUFACTURING AND SERVICES' FIRMS
}

\author{
Artal-Tur, Andrés \\ Technical University of Cartagena \\ Andres.artal@upct.es \\ Navarro-Azorín, José Miguel \\ Technical University of Cartagena \\ Jmiguel.navarro@upct.es \\ Alamá-Sabater, María Luisa \\ University Jaume I at Castellón \\ alama@eco.uji.es \\ García-Sánchez, Antonio \\ Technical University of Cartagena \\ A.garciasanchez@upct.es
}

\begin{abstract}
Focusing on the characteristics of destinations, this paper pursues to identify the role of spatial spillovers in driving location choices of manufacturing and services' firms. With this objective a spatial conditional logit framework is defined, allowing for neighbourhood-related spatial effects. Additionally, a broad indicator of spatial spillovers generated by a given destination is proposed. The model is then applied to empirically capture the behaviour of 1.092 .864 new firms established in 316 municipalities of the Spanish Mediterranean Arc (SMA) between 1998 and 2008. Estimation results show that such spatial effects have a remarkable impact on the location decisions of industrial companies relative to those of services. When the sample is splitted out by technological intensity of activities, it can be observed that spatial spillovers are more willing to affect decisions of high-tech companies relative to those of low-tech ones, particularly for industrial activities.
\end{abstract}

Keywords: destination characteristics, spatial spillovers, location choice, technological intensity.

JEL classification: C31, C35, D22, R12. 


\section{INTRODUCTION}

Studies on the forces driving geographical concentration of economic activity appear as one of the most active topics in today's regional and international literature. As an example, contributions arising from the new economic geography points out towards the explicit consideration of the role of distance, in the form of transport costs, together with increasing returns to scale, when studying the surge of economic centres (FINGLETON, 2007; KRUGMAN, 192). Developments in the spatial econometrics literature provide another important example on that issue (ANSELIN, 2010). Such an interest in restoring spatial dimension in economic studies has even converted agglomeration economies into one of the more scrutinised variables in regional and urban studies, with this variable occupying a salient position when analysing the factors underlying the location choices of agents, such as firms and people (GLAESER, 2010).

In this context, one important feature of studies dealing with agglomeration forces is that these are usually approached as local in nature, that is, the spatial scope of those effects is theoretically bounded to the spatial area that constitutes the unit of analysis, not allowing for real "spill-over" effects. Typically, researchers have measured the magnitude of such externalities within the area of study, say a region or a municipality (ARAUZO et al., 2009). Notwithstanding, recent contributions intend to escape this administrative constrain highlighting the importance that inter-territorial externalities exert in location decisions of agents, in an effort to achieve more realistic modelling of people choices in space (ALAMÁ-SABATER et al., 2010; HOLMES and LEE, 2010; AUTANT-BERNARD and LE SAGE, 2009). These developments are then concerned 
with a new focus when dealing with spatial spillovers, now accounting for the fact that external economies arising in a given geographical destination does not only affect firms localized in that destination, but also could be (and used to be) affecting firms located in nearby destinations. Introducing those forces into theoretical models becomes then necessary, given the relevance that such externalities show in driving location choices (AUTANT-BERNARD, 2006; MOHAMMADIAN and KANAROGLOU, 2003).

This paper continues studying the role that inter-territorial spatial spillovers play in influencing the location choices of firms. The focus is basically directed to improve the way we look at external economies and neighbourhood effects, following the spirit of spatial econometrics exercises. Several contributions are made to the literature. First, a spatially extended discrete choice framework is defined to model the location decisions of firms. Choices are now modelled as a function of individual destinations characteristics, including spatial effects arising from, and affecting to, their surrounding areas. Such a modelling strategy will help to undertake an explicit consideration of geography and externalities in location decisions. This framework will be proven useful in capturing the relative importance that urbanization and specialization economies play in this process, disentangling the very role played by those classical agglomeration economies from other ones arising from additional spatial externalities, locally or not locally bounded. Improving the measurement of the role played by those two agglomeration economies continues to be a matter of concern in this literature, given that both of them constitute the main agglomeration economies identified in mainstream location studies (GLAESER, 2010). 
Second, the empirical model will also be accommodated to account for unobserved spatial effects that may affect the choices of firms, particularly those linked to the inherent spatial heterogeneity characterising locations. Controlling for such unobservable effects is also an important matter in the estimation procedure of the model, given the improvement in the measurement of agglomeration and spatial effects it affords. In pursuing that issue we employ a random effects specification of the spatially extended framework, as suggested by GUIMARÃES et al. (2004).

Third, the empirical exercise is carried out on a new assembled data set including observations of 1.092.864 new firms established in 316 municipalities of the Spanish Mediterranean Arc (SMA) between the years 1998-2008. In that way, the local dimension the data set provides clearly enriches that of previous European studies more focused on the regional or country dimension (AUTANT-BERNARD, 2006; COMBES and OVERMAN, 2004), this being an important issue when trying to capture spatial spillovers that rapidly dissipate with distance (ARAUZO, 2008). Furthermore, since services now represent the bulk of economic activities in modern economies, and the net effects of spatial spillovers can vary considerably among sectors, both manufacturing activities as well as services industries are integrated within the scope of the study, in order to shed light on the different ways spatial effects affect both branches of the economy, this being another novelty in the literature. Finally, and given that technological intensity has become one of the leading indicators when characterising industries and economic sectors in general, the paper will also explore how the technological intensity of firms influence their location decisions, and particularly, if 
spatial effects are more willing to arise in those firms with a higher content of technology in their processes or not.

After this introduction, the structure of the paper remains as follows. Section 2 presents the analytic framework employed in the study. Section 3 is devoted to discuss the choice of the explanatory variables set, estimate the empirical model and discuss the main findings of the investigation. Finally, Section 4 concludes.

\section{MODEL SETTING}

This section introduces a location model based on the standard that the firm will choose the municipality with the highest expected profit among several alternatives. From the point of view of a firm $i$ which operates in industry $s$, each municipality in the set of possible locations offers an expected profit of $\pi_{i j}$ such that

$$
\pi_{i j}=x_{j} \beta+z_{s j} \gamma+\delta\left(W X_{j} \beta+W Z_{s j} \gamma\right)+\eta_{j}+\varepsilon_{i j}
$$

where the variables in $x_{j}$ include those characteristics of the municipality affecting the location decisions of firms in all industries, while $z_{s j}$ just account for those local characteristics affecting the location decisions of firms belonging to the industry $s ; W X_{j}$ and $W Z_{s j}$ are spatially weighted averages of the characteristics of the municipality's neighbours, either common to all industries or relative to a particular one, respectively; $\eta_{j}$ is a municipality random effect capturing the unobservable locational advantages of 
those municipality, ${ }^{1}$ while $\varepsilon_{i j}$ is a random term capturing other unobservable factors that determine the expected profits from locating in municipality $j$ for firm $i .^{2}$

The basic idea underlying the theoretical framework is straightforward, with firms deciding to locate their plants in that municipality more profitable for them, as usual in location theory. Thus, location $j$ is chosen by a firm $i$ if the (expected) profit of choosing such a location is higher than those (expected) of locating in any alternative place. Hence, the probability of choosing location $j$ is:

$$
\operatorname{Pr}\left(\pi_{i j}>\pi_{i k}\right), \text { for } j \neq k \text {, and } j, k=1,2, \ldots, J \text {, }
$$

and it can be shown that if the error term $\varepsilon_{i j}$ is iid according to a type I extreme value distribution, the probability that a firm chooses municipality $j$ conditional on the $\eta_{j}$ 's can be written as:

$$
P_{j \mid s, \eta}=\frac{\exp \left\{x_{j} \beta+z_{s j} \gamma+\delta\left(W X_{j} \beta+W Z_{s j} \gamma\right)+\eta_{j}\right\}}{\sum_{k=1}^{J} \exp \left\{x_{k} \beta+z_{s k} \gamma+\delta\left(W X_{k} \beta+W Z_{s k} \gamma\right)+\eta_{k}\right\}} .
$$

The following relationship for each industry $s$ is the starting point in order to identify the spatial spillovers generated by a given municipality:

$$
1=P_{j \mid s}+\sum_{k \neq j} P_{k \mid s}
$$


where $P_{m \mid s}=E\left(P_{m \mid s, \eta}\right)$ for each location $m$. Then, from equation (4), and given a marginal change in characteristics (common to all industries) of the municipality $j$, the marginal direct and indirect (cross) effects verify:

$$
0=\frac{\partial P_{j \mid s}}{\partial x_{j}}+\sum_{k \neq j} \frac{\partial P_{k \mid s}}{\partial x_{j}} \equiv D E_{j \mid s}+\sum_{k \neq j} I E_{j \rightarrow k \mid s}
$$

Moreover, in the conditional logit setting it follows that the indirect effect of a marginal change in the covariates of the municipality $j$ can be written as:

$$
I E_{j \rightarrow k \mid s}=-P_{j \mid s} P_{k \mid s} \beta+\delta P_{k \mid s}\left(w_{k j}-\sum_{r \neq j} w_{r j} P_{r \mid s}\right) \beta \equiv N S I E_{j \rightarrow k \mid s}+S I E_{j \rightarrow k \mid s} .
$$

The first term in equation (6), or non spatial indirect effect $N S I E_{j \rightarrow k \mid s}$, captures the fact that in the conditional logit framework a change in one of the characteristics of the location $j$ affects its expected profit relative to those of the rest of municipalities and, consequently, induces a change in the ranking of the alternatives which ultimately would modify the distribution of firms across locations. The second term in equation (6), the spatial indirect effect $S I E_{j \rightarrow k \mid s}$, summarizes the effects of changes in the characteristics of municipality $j$ over the probability of another municipality $k$ to attract firms operating within the sector of activity $s$. Note that the intensity of this spatial spillover effect depends on two key elements. First, on the value of $\delta$, so the higher the value of this parameter, the more intense the spatial effects, given that the characteristics of the neighbourhood would receive a greater weight in determining the 
expected profit from locating in a given municipality. Second, the magnitude (and sign) of the spatial spillover also depends on the relevance of the municipality $j$ as a neighbour of municipality $k$, given by the elements of the spatial weigh matrix, $W$. In this sense, closer neighbours to location $k$ in geographical terms would be characterized by a higher value of the corresponding element of the $k$-th row of $W$ and, consequently, the term in parenthesis in equation (6) would be also higher. ${ }^{3}$ Finally, it must be noted that the magnitude of the spatial spillovers from municipality $j$ to municipality $k$ is proportional to the probability $P_{k \mid s}$, that is, the location $k$ would benefit more from spillovers from municipality $j$ whenever it tends to concentrate a higher amount of firms operating in the industry $s$.

A synthetic or compact measure of the spatial spillovers generated by each municipality in the sample, denoted by $S I E_{j \mid s}$, is now computed by integrating the terms $S I E_{j \rightarrow k \mid s}$ over every location $k \neq j:^{4}$

$$
S I E_{j \mid s} \equiv \sum_{k \neq j} S I E_{j \rightarrow k \mid s}=\delta P_{j \mid s} \sum_{k \neq j} w_{k j} P_{k \mid s} \beta
$$

Furthermore, note that the total spatial spillovers generated by a municipality depends on its relative position as attractor of firms $\left(P_{j \mid s}\right)$, showing a bias depending on the size of the municipality, so accordingly it seems appropriate to use a relative measure of spatial spillovers in order to rule out such bias. A relative measure is then defined as the ratio of spatial indirect effects $\left(S I E_{j \mid s}\right)$ to direct effects $\left(D E_{j \mid s}\right)$, that is $\frac{S I E_{j \mid s}}{D E_{j \mid s}}$. Note this 
measure does not depend on the value of the $\beta$ coefficients, thus completing the empirical specification of the model with a standardised (scale-free) measure of spatial spillovers associated to each municipality in the sample.

\section{ESTIMATION RESULTS}

\subsection{DATA DESCRIPTION}

The analysis in this paper draws on a data set for the population of firms established in the Spanish Mediterranean Arc (SMA) provided by the Spanish National Statistics Institute (INE). The SMA is here defined as the territory of the Spanish Mediterranean coastal area stretching from the French frontier to the Straits of Gibraltar, that is, between the regions of Catalonia and Andalusia. Because of differences in levels of economic development, infrastructures, and competitiveness, Catalonia and Valencia show a more favourable position in a wide range of economic indicators in comparison with the other two regions making the SMA, that is, Murcia and Andalusia.

The areas that make up the SMA constitute 40.9\% (approximately 19 million inhabitants) of the population of Spain (3.8\% of EU-27); $18.9 \%$ of the surface area of Spain (2.2\% of EU-27); and their GDP represents $40.6 \%$ of Spain (3.7\% of EU-27). Thus, the SMA as a geographical unit concentrates more than $40 \%$ of Spanish population and economic activity in less than $20 \%$ of the total country surface. Through the last decades the area has registered an important demographic growth (boosted by migratory flows), resulting in high population densities, particularly on the seaboard. 
Other distinctive characteristics of the SMA include a strong specialization in tourism and leisure related activities which exploit environmental advantages (climate, landscape, etc.). Moreover, the manufacturing sector rests on SMEs mainly concentrated on traditional activities.

A detailed analysis of the spatial configuration of the SMA reveals the existence of two territorial imbalances which are in turn reinforced by a still improvable articulation of transport infrastructures. First, there is a remarkable contrast between the active and densely populated seaboard and the rather inhabited inlands. Secondly, there exists a discontinuity in the urban network. Southwards, it appears Barcelona's urban agglomeration, the metropolitan area of Valencia, and a set of coastal cities from Benidorm (Alicante) to Cartagena (Murcia). At this point takes place a marked decline of urbanized areas in the extension of the SMA to Andalusia (except for the metropolitan area of Málaga). Furthermore, in the whole area under study, two cities, Barcelona and Valencia, make the difference in terms of global connectivity, both of them becoming well consolidated urban structures connected to the rest of Europe. Finally, note that this last imbalance is consistent with the already stated minor relative development of the southern regions making SMA.

In this context, the data set comprises 1.092 .864 new plants located in 316 municipalities between 1998 and 2008. Since services now occupy a large proportion of jobs in the SMA, they are worth of attention and, departing from other studies on activity location more traditionally focused on the manufacturing sector, both, services and manufacturing firms are included in the analysis. The spatial distribution of the 
firms among the SMA municipalities is depicted in Figure 1, where it is clearly showed that a large proportion of firms are established in the urban metropolitan areas of Barcelona and Valencia, together with those municipalities located in the seaside corridor (it should be added that, in general, administrative centres tend to be located in this area).

A deeper descriptive look at the spatial distribution of firms in the SMA can be obtained by using the local Getis-Ord statistic, which is displayed in Figure 2 for each defined sub-sample of industries. It shows that municipalities with the higher concentration of firms are localized in the coast, and particularly in the metropolitan area of Barcelona. The result holds as well for manufactures and services and, to some extent, justifies a preliminary divide between a vibrant-agglomerated-environment centred in Barcelona and the remainder of the SMA. Notwithstanding, a closer look at the figure suggests that the metropolitan area of Valencia also defines a hot spot for every sector of activity, together with municipalities in the South of Alicante for low-tech manufactures and a set of locations in the coastal fringe of Malaga for the case of low-tech services.

\subsection{EXPLANATORY VARIABLES}

Table 1 summarizes the list of explanatory variables considered as potential determinants of the location of firms in the SMA, along with its exact definition. The list of explanatory variables includes a set of dummies to account for potential differences in the institutional environment which are mainly determined by the Autonomous Community to which the municipality belongs to. Spanish Autonomous 
Communities (corresponding to the NUTS-2 regions of the European Union) are the first-level administrative divisions and are responsible to a great extent of a wide range of relevant aspects of industrial policy, such as innovation policy, taxes, subsidies, etc., which ultimately determine the costs of establishment for new companies, so it is important to include those as control variables.

Distance to head, measured by Euclidean distance to the administrative head of the related provincia, ${ }^{5}$ will act as a proxy for accessibility (transport costs) of the municipality, as the design of the infrastructure network in Spain tends to favour these administrative centres. Then the distance to administrative heads can be thought of as a measure of accessibility to the municipality or, alternatively, as transportation and distribution costs faced by firms located in every municipality.

Local level of population is included in the model as a measure of market size. In the absence of detailed local data on variables, such as personal income, that would better accounting for market attractiveness, total population emerges as a reasonable proxy for potential consumers' demand (KRUGMAN, 1992). However, the explanatory performance of this proxy may be low as the relevant market for a large proportion of the firms does not necessarily exactly matches the municipality area.

Urban population density is used to proxy land price since industrial and residential users compete for land. This is a cost variable and consequently it is expected to exert a negative influence on the probability of choosing a municipality. Also could capture some congestion effects due to high levels of density in urban environments. 
The availability of human capital stock is often cited as a source of observed differentials in productivity among firms and regions. Access to a more qualified workforce implies that firms can introduce advanced production techniques faster, that they can adopt new innovations easily and that new knowledge from both the industry and other industries (knowledge spillovers) can be absorbed in a much easier way. Thus firms would tend to locate in municipalities with a more educated workforce as it can boost their ability to benefit more from inter-industry knowledge spillovers and their productivity. Agglomeration economies arising from labour market pooling provide another benchmark for this type of positive effects arising from an educated local workforce (GLAESER, 2010). Along these lines, the set of covariates includes the share of the workforce who has attained a University degree as a proxy for the stock of human capital. Human capital is expected to favour location choices on a targeted municipality.

Beyond these factors, firms' decisions on their localization can also be driven by both intra-industry (localization economies) and inter-industry (urbanization economies) agglomeration effects or externalities. In this respect, a firm located in close proximity to other firms in the same industry can take advantage of a range of intra-industry benefits, including access to specialized know-how, sharing of sector specific skilled labour, integration in buyer-supplier networks, opportunities for efficient subcontracting, etc. As a result, the co-location of firms in the same industry generates cluster externalities that enhance productivity of all firms in that industry, increasing local attractiveness for the localization of new firms operating in that industry. The location quotient for each industry in each municipality is used to capture the effects (if any) of localization economies. This measure identifies the degree to which any given 
municipality is specialized in any given economic activity and it is expected to exert a positive effect on the probability of a generic firm to locate in the municipality.

Firms can also benefit from being located in close proximity to firms in other industries. These inter-industry advantages include easier access to complementary services, availability of a large labour pool with multiple specializations, and the availability of general infrastructure and a vibrant socio-economic ambient (JACOBS, 1969). Urbanization economies stem from the overall size and diversity of the urban agglomeration. However, size is usually correlated with diversity as larger urban areas can support a wider range of economic activities. Among the defined explanatory variables set there are two related with size (measure by the concentration of firms per squared kilometre in each municipality) and diversity (measured by the inverse of the Herfindahl-Hirschmann index of concentration), both measuring some dimension of urbanization economies. Even though these variables are expected to exert a positive effect on location choices, it may be also the case that agglomeration of firms in a given municipality generates negative externalities due to the increased competition for limited infrastructures, specialized services, or workforce, among other factors.

The spatial weight matrix $W$ is defined in terms of the inverse Euclidean distances among municipalities, with a representative term:

$$
w_{j l}=\left\{\begin{array}{cc}
d_{j l}^{-1} / \sum_{l=1}^{J} d_{j l}^{-1} & \text { if } d_{j l} \leq R \\
0 & \text { otherwise }
\end{array}\right.
$$


where $d_{j l}$ is the Euclidean distance between municipality $j$ and municipality $l$, and $R$ represents a critical distance determining the range of action of spatial effects, if present. Note that, by construction, $w_{j l}$ satisfies $w_{j l}=w_{l j}, w_{j j}=0$, and $\sum_{j} w_{j l}=1$. In order to determining the most appropriate value for the parameter $R$, it is adopted the approach proposed by FERSTL (2007). This implies computing the Moran's I statistic for spatial correlation for different values of $R$ and selecting a value $R_{o p t}$ such that:

$$
R_{o p t}=\arg \min _{R}\left|z_{\mathrm{I}}\left(y^{*}\right)\right|, \quad 0<R<+\infty,
$$

where $z_{\mathrm{I}}\left(y^{*}\right)$ is the standardized Moran's I statistic for the spatially filtered data (GETIS and ORD, 1995).

\subsection{ESTIMATES}

This section estimates a spatial location model allowing for spatial spillovers affecting localization choices of new firms in the period 1998-2008 in the Spanish Mediterranean Arc (SMA). It is assumed that the relevance of factors affecting location choices may vary according to the own characteristics of the industry the firm belongs to. Consequently, the whole sample is splitted out into four sub-samples, estimating a model for manufacturing and services firms separately, and also taking into account the existence of high and low technological activities among these two great sectors of activity. Industries included in every subsector are shown in Table 2. 
Table 3 presents the estimation results obtained for different sectors of activity, from where it can be drawn some general conclusions about the role played by every explanatory variable included in the preferred specification of the empirical model. In general, every parameter show the expected sign and their magnitudes match with those found by the comparable literature employing logit models in location choice analysis. All continuous variables are in logs, so obtained estimates for coefficients reflect the elasticity (of the probability) of choosing a particular municipality with respect to the explanatory variable. ${ }^{6}$

Regarding the regional dummies, but for the Region of Murcia, there seems to be no significant differences among the regions under study with respect to the reference category (Valencian region). This result suggests that the SMA institutional framework is fairly uniform, with the exception of the Region of Murcia, which is the smallest region of the SMA, and exhibits a noticeable dynamism in firm birth rates in recent times with important institutional incentives, what seems to be captured by the regional effects parameter.

The distance to administrative head has a negative influence on location choice, but the effect is only significant for firms operating in high-tech industrial activities. Therefore, even although accessibility may be a highly relevant factor determining the location choices by firms, for municipalities in the SMA distances to administrative heads (associated with the largest urban centres) are not too large so as to impose an appreciable penalty to firms localized in the more peripheral municipalities. Regarding this result, while a good access to market centres (or location close to large urban 
centres) can encourage interaction and knowledge spillovers between firms, research institutions and governmental and regulatory authorities, these benefits can be offset by costs derived from enhanced competition among firms, such as increases in land rents, wages, or commuting times for workers. Accordingly, congestion costs associated to the localization of firms close to the administrative centres are likely to play a relevant role as a determinant of location choices. It can be also the case that accessibility to other knots, such as maritime terminals, airports, etc., would be more relevant to firms than proximity to the administrative heads, this being an issue to explore in further work.

Location choice appears to be influenced positively by the local stock of human capital. Moreover, this is one of the most relevant determinants in the four subsamples, if not the most, showing the higher capability in magnitude in influencing location choices after spatial spillovers. The estimated coefficient indicates that a municipality that experiences a $10 \%$ rise in the proxy for human capital would increase the probability of being chosen in the future from $5.8 \%$ to $7.5 \%$, the last figure for the case of firms belonging to the high-tech services.

The total municipality population exhibits the expected (positive) sign and appears statistically significant. As pointed out before, this independent variable is used to proxy the market size, hence the results suggests that location choices by firms seems to be guided by the benefits of locating production activities in areas which implies a higher potential demand for firm's products, and effect appearing particularly relevant for high-tech services as expected. 
Urban population density is statistically significant with a negative sign in all the sectors considered. These results confirm land costs as a relevant factor for location decisions, although it appears to be more influential for services than for manufacturing industries, and in particular for high-tech activities. In this sense, an increase of $10 \%$ in the urban population density of a municipality would reduce the probability of being the preferred location from $2.2 \%$ in the case of low-tech manufactures to $4.3 \%$ for high-tech service activities. This might reflect a higher propensity of service firms to locate closer to urban centres, thus facing up a more intense competence for land with residential users Congestion costs are also beside this result, a problem that seems to be more present for services, given that those activities usually choose locations closer to the city centre in comparison with manufactures.

The two dimensions (size and diversity) of urbanization economies are taken into account by the firm density per squared kilometre and the diversification index of economic activity in each municipality. For the first variable, the results reveal the presence of positive agglomeration effects; the location of firms, independently of their economic sector of activity, imparts a consistently positive and significant impact on the attractiveness of potential host municipalities. Notwithstanding, contrary to prior expectations, the diversity index has a negative influence on location choice, but the effect for high-tech industries is not significant. The effect of diversity is also substantially higher for location decisions of firms operating in high-tech activities, so that a $10 \%$ increase in the index of economic diversity in a municipality would lead to a reduction of $7.5 \%$ (low-tech industries) and of $8.7 \%$ (low-tech services) in its 
probability of being the destination for these types of firms in the future, still reflecting certain preference for specialised environments.

The estimated coefficients for the specialization quotients are positive and significant, indicating that firms tend to exploit benefits of intra-industry clustering in their location choices. However these effects are more intense for firms in low-tech sectors, and especially in the manufactures, with an elasticity value near to 0.9 . This result is consistent with the available empirical evidence on geographical distribution of industrial firms in the SMA; for example, (BOIX and GALLETTO, 2006) identifies a sizeable number of clusters of firms (local production systems) dedicated to traditional manufactures localized in the SMA.

The econometric model includes a term to capture potential spatial effects affecting firms' choices. These effects are summarized by the $\delta$ parameter; this parameter measures the relative importance of the local neighbourhood in determining firms' choices. Spatial effects are significant albeit they exhibit a rather wide range of values, from 0.06 to 0.62 for industry and from 0.25 to 0.36 for services. Spatial effects are more pronounced for high-tech industry firms, while for low-tech industrial firms neighbourhood seems to be not so relevant (the estimated coefficient is 0.06), or perhaps external effects are basically of the type locally bounded, with less importance of the inter-municipal spatial effects. According to this result, firms in the high-tech manufactures exhibit a more pronounced tendency to look for sources of positive externalities (via knowledge sharing, labour market pooling, etc.), beyond the municipality where they are localized as compared to other firms in the low-tech 
industries. This result is widely consistent with the fact that access to knowledge should be particularly relevant as a search strategy for high-tech industries, and consequently, there are evident potential benefits from co-location in municipalities' networks. This is also consistent with one of the empirical findings concerning the relevance of localization economies emerging from the very own municipality were the firm is located (a lower coefficient is estimated for the corresponding explanatory variable, the location quotients, in the case of high-tech manufactures).

Turning to the services activities, the local neighbourhood seems to exert a rather moderate effect in the location decisions of services firms, especially when compared with high-tech manufacturing firms, although always higher enough than those characterising low-tech manufactures. Then, for services activities it seems to emerge a sort of home market effect, that is, such companies could potentially obtain enough local demand to exploit economies of scale, thus lessening the importance of the neighbourhood, as was the case of low-tech industries (KRUGMAN, 1992). Moreover, this effect seems to be of a comparable magnitude in both high-tech and low-tech services, inside a confidence interval for estimated parameters of the $\delta$ variable.

The conditional logit model also includes a random term $\left(\eta_{j}\right)$, which is a factor defined to capture the effects of unobserved exogenous variables at the municipality level, such as cultural and geographical characteristics. As suggested by GUIMARÃES et al. (2004), if the independence from irrelevant alternatives assumption is interpreted as an omitted explanatory variables problem, the random effect would contribute to mitigate this drawback of the conditional logit model. 


\subsection{MAPPING SPATIAL SPILLOVERS}

The conditional logit model provides a convenient framework to investigate the spillover effect generated by changes in the characteristics of each municipality through its impacts in the surrounding environment of other municipalities in the SMA. As noted above, these effects come from two sources: the first one is induced by the model specification (that is, this effect would be also present in a not spatially augmented conditional logit model), while the second is due to the explicit recognition of the possibility of spatial effects in the firm location choice (this effect would only appear if the conditional logit model is augmented to include spatially weighted explanatory variables). Regarding the former source, a marginal and positive change in one of the explanatory variables in the municipality $j$ would improve the expected profits from choosing that location, thus decreasing the attractiveness of the other potential destinations for firms (direct effect). The spatial indirect effect arise because, given the marginal change in a covariate characterising the municipality $j$, it also would result in an improvement of the expected profits from locating in other neighbouring municipalities, which in turn will increase their attractiveness for the localization of firms.

Figure 3 depicts the distribution of the estimated spatial spillovers caused by marginal changes of characteristics of every individual municipality in the sample. ${ }^{7}$ To interpret correctly these results it must be underlined that the magnitude of the spatial spillovers linked to a given municipality remains a function of two basic factors. First, it depends on how much relevance firms assign to the neighbourhood area characteristics when 
computing their expected profits of locating in a particular destination; and this is controlled by the $\delta$ parameter. In this sense, for the case of the high-tech manufactures it is obtained the highest estimated value for the parameter $\delta$ and, accordingly, overall spatial spillovers are more relevant for this type of economic activities as compared with low-tech industries and services. Secondly, the magnitude of the spatial spillovers associated to a given location is determined by the average distance to other municipalities as they contribute to shape the characteristics of the neighbouring area, thus increasing the expected profits from locating in that municipality. Subsequently, municipalities integrated in dense urban networks should exhibit the greatest capability to generate spatial spillovers, being this effect particularly evident for the municipalities included in the metropolitan areas of Barcelona and Valencia, where neighbour municipalities reinforce each other their spatial effects through indirect channels (see equation 6).

In the case of high-tech manufactures, from Figure 3 it is clear that the main focus of spatial spillovers is defined by Barcelona and municipalities located in its vicinity. This result is explained by both the high concentration of firms operating in this sector of activity in these locations, and the geographical proximity among them. Furthermore, municipalities in the metropolitan area of Valencia also display a noticeable ability to generate spatial spillovers, together with some locations in the South which concentrate firms operating in the manufacture of transport equipment. For the case of low-tech manufactures, apart from the metropolitan areas of Valencia and Barcelona, a group of municipalities in the provincia of Alicante reveal themselves as relevant sources of 
spatial spillovers. These municipalities exhibit a high specialization (and concentration) of light industry firms (mainly footwear and leather manufactures).

Regarding the services sector some interesting remarks arise from Figure 3. For hightech services, in general, those municipalities showing the highest capability of generating spillovers coincide with administrative heads (which barely match the largest municipalities in the SMA). It could be explained because such administrative heads tend to constitute the centre of the urban networks, in contrast with other municipalities of the SMA which appear rather geographically isolated. Regarding low-tech services, and given the relevance of tourism related activities in the SMA, municipalities with the greatest potential to generate spatial spillovers are clearly those located into the main tourism destinations in the SMA, including Barcelona and the coastal area of Alicante, Málaga and Cádiz, given the relevance that sun and sand products still detent in the whole national and European tourism market.

These results, considered as a whole, are consistent with a centre-periphery model of agglomeration for the SMA space, given that those municipalities located in the seaside reinforce their spatial effects each other, while inland localities are going to be losing attractiveness for new firms progressively, given the behaviour underlying the model specification (PÓLESE and SHEARMUR, 2006). Because of that reason, in this particular case Cohesion and Regional European funds appear to be of great relevance in order to offset centrifugal forces, thus making a decisive contribution to balance the location of economic agents, such as firms and population, in the territory. The same could be applied to the rest of EU regions, especially for Southern ones, so the results of 
this exercise are of clear relevance from the EU regional policy point of view (PUGA, 2002).

\section{CONCLUSIONS}

Introducing space in location analyses is of major interest for regional and urban studies. This paper studies the quantitative relevance of spatial spillovers for firms' location choices at the municipality level within the Spanish Mediterranean Arc. In contrast with previous empirical studies, the present study accounts for the potential influence of such external economies emerging from the surrounding area of each municipality, thus incorporating in the analysis this important issue not so much present yet in the literature. With this objective, a spatial conditional logit is estimated to evaluate the relative weight of space in shaping firms' location choices. Additionally, the empirical model distinguishes among the corresponding spatial effects explained or associated to the characteristics of the own chosen municipality relative to those effects linked to the own features of the neighbouring area, here labelled as spatial spillovers. Further from the explicit consideration of space in a discrete choice framework, the second main contribution of this paper to the empirical literature has been the inclusion of both manufacturing and service industries in the analysis, together with the focus on municipal data, what seems to be the better and correct way to approach and measure such spillovers. The relevance of spatial externalities in influencing firms' choices and its relation to the technological content of the economic activity has been also analysed. By doing so, it is explicitly recognized that the net effects of agglomeration economies 
and spatial effects may vary considerably among sectors, this being other important topic which deserves a more indeed treatment in the related literature.

The empirical results support the hypothesis that inter-territorial spatial effects clearly matter for the location decisions of firms in manufacturing and service industries. Moreover, these findings support the view that, beyond the characteristics of each potential location, firms also take into account the features of the neighbouring locations in order to decide where to stay. However, the empirical relevance of space in the firms' decision process is found to vary according to the different economic sectors of activity. In this regard, the neighbouring area characteristics seems to be much more relevant in the high-tech manufacturing industries as compared with the services activities, which seems to be more focused on the own municipality characteristics, given the relevance of effects associated to the size of the local market and agglomeration effects locally bounded. Human capital also continues to play a significant role in location choices for every sector in the investigation.

The explicit inclusion of space in the model specification also led to identify new channels through which changes in the characteristics of one municipality could affect the attractiveness of other municipalities from the perspective of localization of establishments. These effects have been defined as spatial spillovers and have served as a way to measure to which extent changes in one municipality are more or less relevant according to its relative impact over the rest of the municipalities, a pivotal insight still not developed in location literature, but with a great role in explaining location choices as noted in the paper. Moreover, and from the perspective of the regional policy 
recommendations emerging from the results of the investigation, this paper has addressed the need of defining differentiated policies for industry and services activities, also depending on their technological content. Policies aimed to enhance the attractiveness of municipalities, as potential destinations for the establishment of new companies, must be aware of the specialisation patterns that characterise the area under study, taking into account that the success of such policies may vary depending on the sector of activity characterising the locality. 


\section{REFERENCES}

ALAMÁ-SABATER, L., ARTAL-TUR, A., and NAVARRO-AZORÍN J M (2010) Industrial location, spatial discrete choice models and the need to account for neighbourhood effects, Annals of Regional Science, forthcoming. DOI: 10.1007/s00168-010-0383-7.

ANSELIN, L. (2010) 30 years of Spatial Econometrics, Papers in Regional Science, 89(1), 3-25.

ARAUZO, J. M. (2008) Industrial location at a local level: Comments on the territorial level of analysis, Journal of Economic Social Geography, 99, 193-208.

ARAUZO, J. M., LIVIANO, D., and MANJÓN, M. (2009) Empirical studies in industrial location: An assessment of their methods and results, Journal of Regional Science, XX (X), 1-32.

AUTANT-BERNARD, C. (2006) Where do firms choose to locate their R\&D?. A spatial conditional logit analysis on French data, European Planning Studies, 14(9), 1187-1208.

AUTANT-BERNARD, C., and LE SAGE, J. (2009) Quantifying knowledge spillovers using Spatial Econometric tools, Journal of Regional Science, forthcoming.

BOIX, R., and GALLETTO, V. (2006) Sistemas locales de empleo y distritos marshallianos en España, Economía Industrial, 359, 165-184.

COMBES P. P., and OVERMAN H. G. (2004) The Spatial Distribution of Economic Activities in the European Union, In: Henderson V. and Thisse J. F. (eds.), Handbook of Urban and Regional Economics, Volume 4, North-Holland: Elsevier, 88-134.

FERSTL, R. (2007) Spatial filtering with EViews and MATLAB, Austrian Journal of Statistics, 36, 17-26.

FINGLETON, B. (2007) New directions in Economic Geography. Cheltenham: Edward Elgar.

GETIS, A., and ORD, J. (1995) Local spatial autocorrelation statistics: distributional issues and an application, Journal of Geographical Analysis, 27, 286-305. 
GLAESER, E. L. (2010) Agglomeration Economics. Chicago:NBER-Univesity of Chicago Press.

GUIMARÃES, P., FIGUEIREDO, O., and WOODWARD, D. (2004) Industrial location modeling: Extending the random utility framework, Journal of Regional Science, 44, 1-20.

HEAD, K., RIES, J., and SWANSON, D. (1995) Agglomeration benefits and location choice: Evidence from Japanese manufacturing investments in the United States, Journal of International Economics, 38, 223-247.

HOLMES, T. J., and LEE, S. (2010) Citied as Six-by-Six Mile Squares: Zipf's Law?" in GLAESER E. L. (2010), Agglomeration Economics. Chicago: NBER-University of Chicago Press.

JACOBS J (1969) The Economy of Cities, New York: Random House.

KRUGMAN, P. A. (1992) Geography and Trade, Cambridge (Mass): MIT Press.

LE SAGE, J., and PACE, R. K. (2009) Introduction to Spatial Econometrics. Taylor and Francis Group.

MOHAMMADIAN A., and KANAROGLOU, P. S. (2003) Applications of Spatial Multinomial Logit Model to Transportation Planning, Communication presented at the 10th International Conference on Travel Behaviour Research, 10-15 Aug, Lucerne.

PÓLESE M., and SHEARMUR R. (2006) Why some regions will decline: A Canadian case study with thoughts on local development strategies, Papers in Regional Science, 85 (1), 23-46.

PUGA, D. (2002) European regional policies in light of recent location theories, Journal of Economic Geography, 2(4), 373-406. 


\section{TABLES}

Table 1: Independent variables: definition and data sources

\begin{tabular}{|c|c|c|}
\hline Variable & Definition & Source \\
\hline $\begin{array}{l}\text { RCAT, RMUR, } \\
\text { RAND }\end{array}$ & $\begin{array}{l}\text { Dummies for NUTS } 2 \text { regions (Catalonia, Region of } \\
\text { Murcia, Andalusia). The reference category is the } \\
\text { Valencian Region }\end{array}$ & Own elaboration \\
\hline DISTHEAD & Distance to administrative head in kilometres & Own elaboration \\
\hline $\mathrm{HC} 3$ & $\begin{array}{l}\text { Ratio of labour force having attained a } \\
\text { higher education degree to total labour force }\end{array}$ & INE \\
\hline POPULAT & Number of inhabitants in the municipality & Censo (INE) \\
\hline POPDEN & Urban population per squared kilometre & $\begin{array}{l}\text { Censo (INE) and } \\
\text { own elaboration }\end{array}$ \\
\hline FIRMDEN & Number of firms per squared kilometre & DIRCE \\
\hline DIVERS & $\begin{array}{l}\text { Index of diversification computed as } H^{-1} \text {, where } \\
H=\sum_{s} c_{s}^{2} \text { and } c_{s} \text { is the share of the number of firms } \\
\text { in industry } s \text { over total firms for each municipality }\end{array}$ & $\begin{array}{l}\text { Own elaboration } \\
\text { from DIRCE data }\end{array}$ \\
\hline FESPSECT & Coefficient of specialization & $\begin{array}{l}\text { Own elaboration } \\
\text { from DIRCE data }\end{array}$ \\
\hline
\end{tabular}


Table 2: Classification of economic activities

\begin{tabular}{llc}
\hline & Economic activities & ISIC \\
\hline High-tech manufactures & Manufacture of chemical indus try & 24 \\
& N.E.C. machinery and equipment & 29 \\
& Office machinery, computing machinery & 30 \\
& N.E.C. el ectrical machinery apparatus & 31 \\
& Radio, TV and Communication equipment & 32 \\
& Medical, precise, optical instruments & 33 \\
& Manufacture of motor vehicles and trailers & 34 \\
& Other transport equipment & 35 \\
\hline Low-tech manufactures & Food products and beverages. Tobacco products & 15,16 \\
& Textile products & 17 \\
& Wearing apparel & 18 \\
& Dressing of leather & 19 \\
& Wood products (except furniture) & 20 \\
& Manufacture of paper and paper product & 21 \\
& Publishing and printing & 22 \\
& Other manufactures & 36 \\
\hline High-tech services & Post and telecommunications & 64 \\
& Computer and related activities & 72 \\
& Commercial R\&D services & 73 \\
\hline Low-tech services & Wholesale and retail trades. Hotels and restaurants & $50,51,52,55$ \\
& Land, water, air transport and supporting services & $60,61,62,63$ \\
& Finance \& insurance & $65,66,67$ \\
& Real state activities. Business support activities & $70,71,74$ \\
\hline
\end{tabular}


Table 3: Location choice of firms in the Spanish Mediterranean Arc (SMA): spatial conditional logit model

\begin{tabular}{|c|c|c|c|c|}
\hline \multirow[b]{2}{*}{ Parameters } & \multicolumn{2}{|c|}{ Manufactures } & \multicolumn{2}{|c|}{ Services } \\
\hline & High-tech & Low-tech & High-tech & Low-tech \\
\hline RCAT & -0.0157 & 0.0873 & 0.0821 & 0.0635 \\
\hline RMUR & $0.2676^{* * *}$ & $0.2815^{* * *}$ & $0.3226^{* * *}$ & $0.3389^{* *}$ \\
\hline RAND & -0.0152 & 0.0578 & 0.0320 & -0.0 \\
\hline DISTHEAD & $-0.0706^{* *}$ & -0.0130 & -0.0423 & -0.0366 \\
\hline HC3 & $0.5805^{* * *}$ & $0.6002^{* * *}$ & $0.7545^{* * *}$ & $0.6073^{* *}$ \\
\hline POPULAT & $0.1987^{* * *}$ & $0.2669^{* * *}$ & $0.3986^{* * *}$ & $0.2391^{* * *}$ \\
\hline POPDEN & $-0.2853^{* * *}$ & $-0.2264^{* * *}$ & $-0.4318^{* * *}$ & $-0.3167^{*}$ \\
\hline FIRMDEN & $0.1348^{* * *}$ & $0.1919^{* * *}$ & $0.2791^{* * *}$ & $0.2327^{* * *}$ \\
\hline DIVERS & -0.1954 & $-0.7482^{* * *}$ & $-0.3899^{* *}$ & $-0.8715^{* * *}$ \\
\hline FESPSECT & $0.4329^{* * *}$ & $0.8934^{* * *}$ & $0.1997^{* * *}$ & $0.7613^{* * *}$ \\
\hline$\delta$ & $0.6217^{* * *}$ & $0.0655^{* * *}$ & $0.2583^{* *}$ & $0.3616^{* * *}$ \\
\hline $\ln (\eta)$ & $1.4453^{* * *}$ & $1.4699^{* * *}$ & $1.4869^{* * *}$ & $1.4902^{* * *}$ \\
\hline
\end{tabular}

Notes: The dependent variable is location choice of new firms.

Significance of coefficients at $* * * 1 \%, * * 5 \%, * 10 \%$. 


\section{FIGURES}

Figure 1. Geographical distribution of firms in the Spanish Mediterranean Arc (SMA)

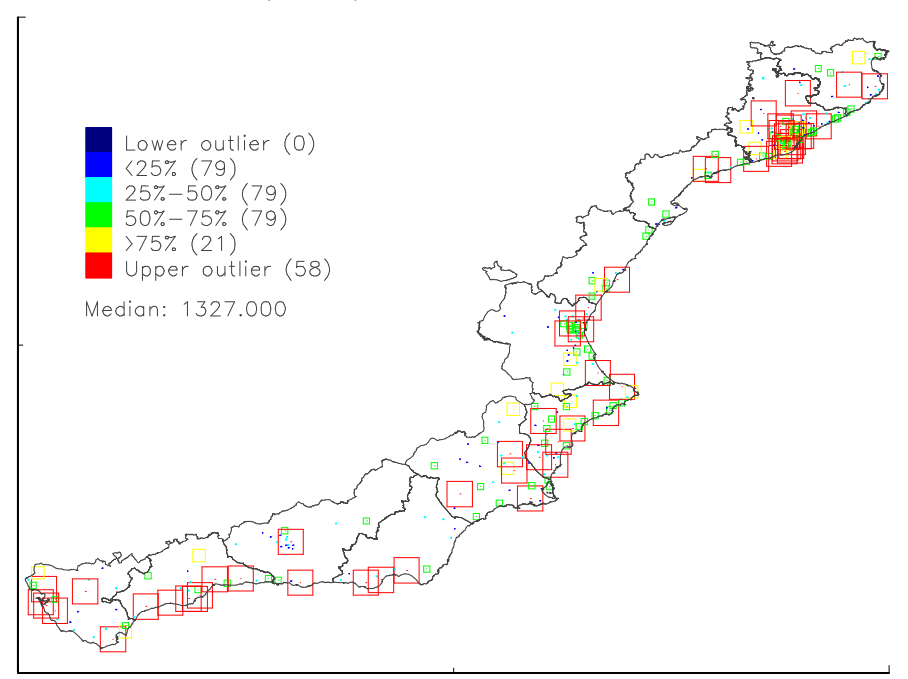


Figure2. High/low clustering (local Getis-Ord $G_{i}^{*}$ statistic).

High-tech manufactures
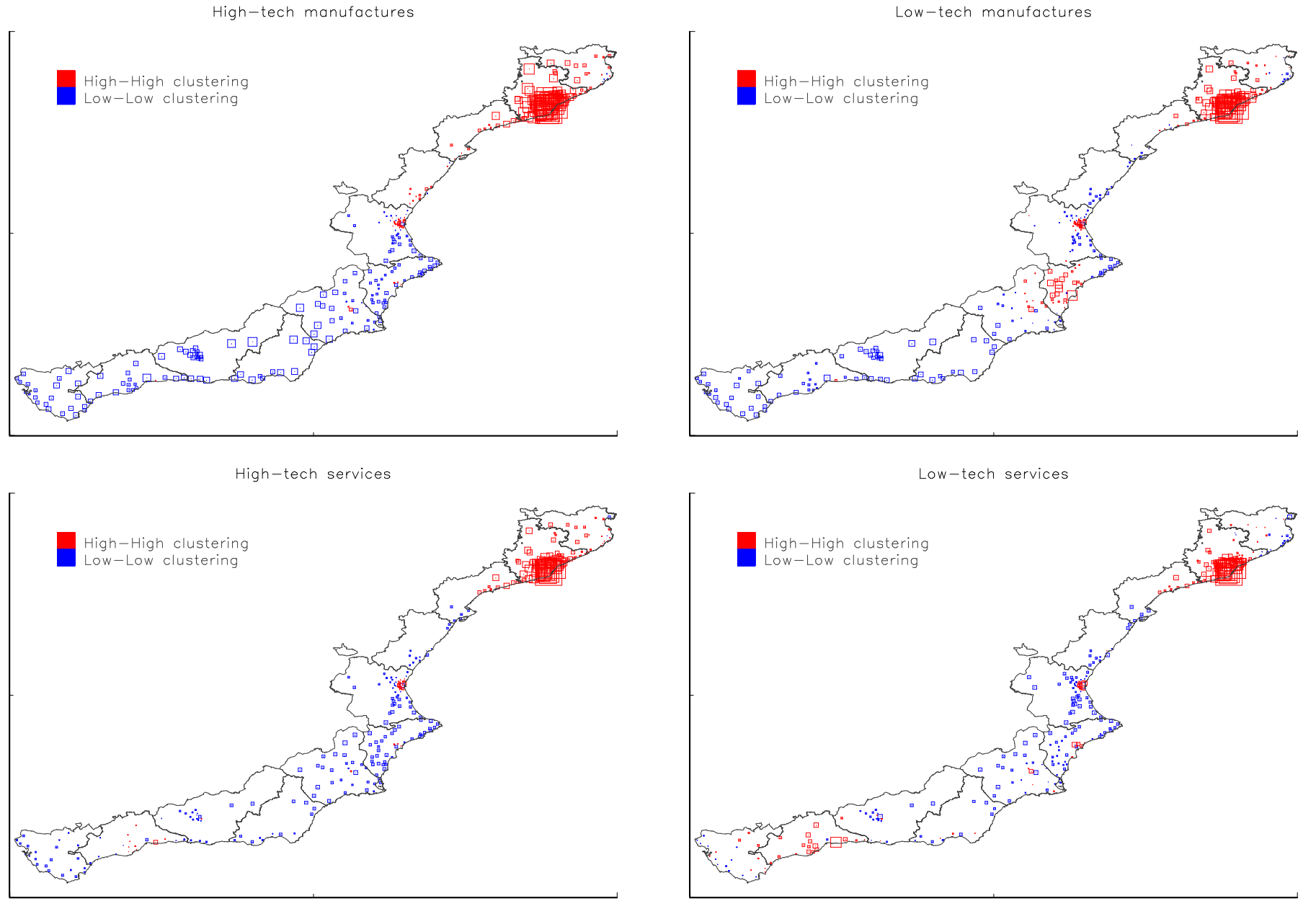
Figure 3. Geographical distribution of spatial spillovers from each municipality. High-tech manufactures: $S I E_{j} / D E_{j}$ ratio Low-tech manufactures: $\mathrm{SE}_{\mathrm{j}} / \mathrm{DE}_{\mathrm{j}}$ ratio
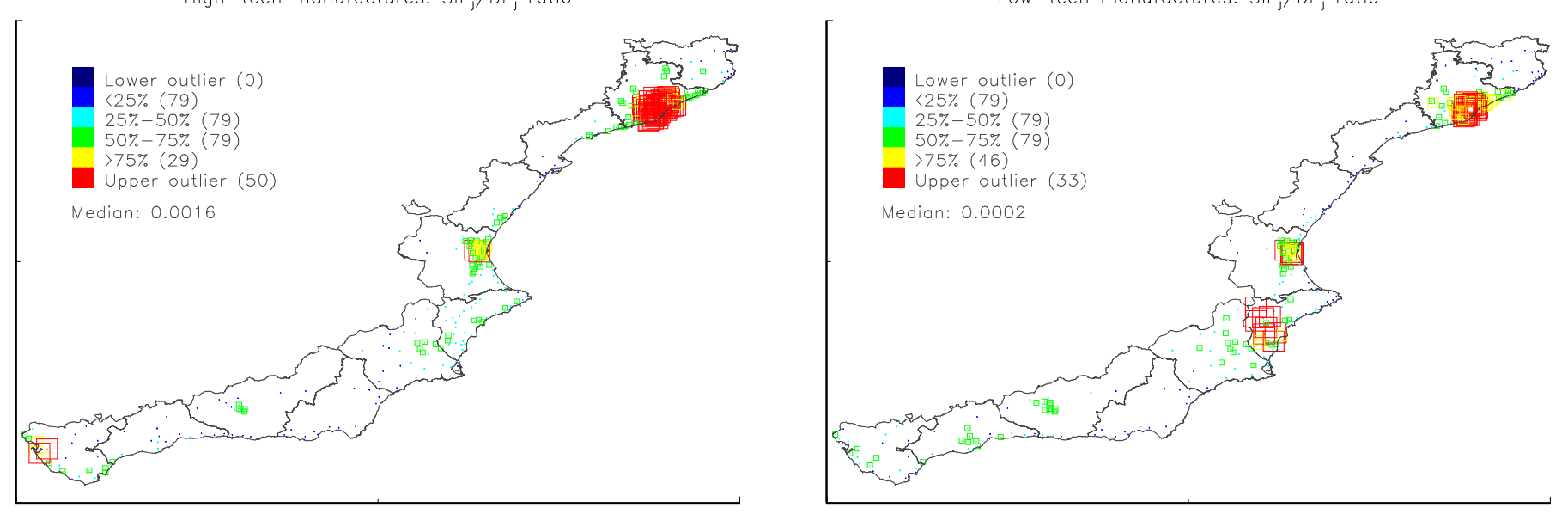

High-tech services: $\mathrm{SIE}_{\mathrm{j}} / \mathrm{DE} \mathrm{E}_{\mathrm{j}}$ ratio

Low-tech services: $S I \mathrm{E}_{\mathrm{j}} / \mathrm{DE} \mathrm{E}_{\mathrm{j}}$ ratio
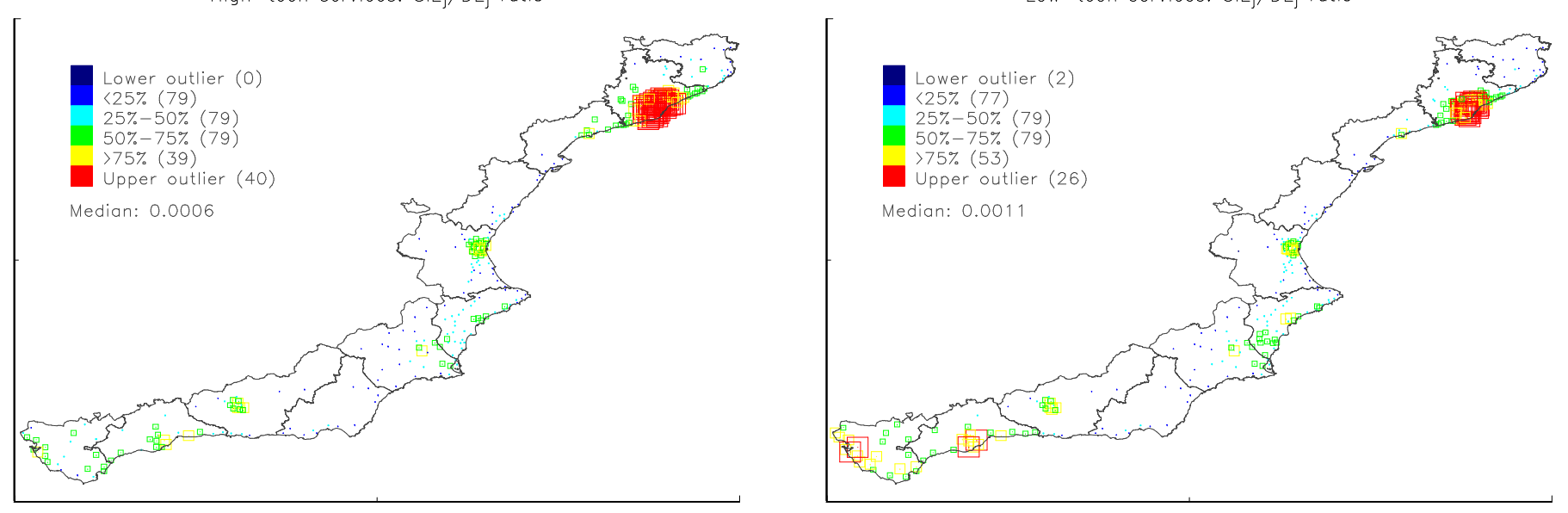


\section{NOTES}

${ }^{1}$ It is assumed that the $\exp \left(\eta_{j}\right)$ 's are iid with a Gamma distribution with parameters $(\eta, \eta)$ so that $\operatorname{E}\left(\exp \left(\eta_{j}\right)\right)=1$ and $\operatorname{Var}\left(\exp \left(\eta_{j}\right)\right)=\eta^{-1}$.

${ }^{2}$ This model spatially extends the original contribution to location framework developed in GUIMARÃES et al.(2004).

${ }^{3}$ Note that the term $w_{k j}$ is inversely related to the geographical distance between locations $k$ and $j$, while $\sum_{r \neq j} w_{r j} P_{r \mid s}$ is a weighted average of elements of the terms in the $k$-th row of the $W$ matrix. Thus, if $w_{k j}$ is greater than the average, the spatial spillover would be positive, and negative otherwise.

${ }^{4}$ This summary measure of generated spatial spillovers resembles the Total Impact from an Observation Measure introduced in LESAGE and PACE (2009).

${ }^{5}$ Spanish provincias are intermediate administrative levels composed of several adjacent municipalities in the same region or autonomous community.

${ }^{6}$ Without taking into account spatial effects, the relationship between the average probability elasticity and the coefficient estimate $\beta_{k}$ is $\varepsilon_{k}=\frac{J-1}{J} \beta_{k}$ where $J$ represents the number of choices (see HEAD et al., 1995). Consequently, as $J$ gets larger (as is the present case), average probabilities gets closer to the parameter estimates.

${ }^{7}$ Note that from the model estimates it is possible to construct a measure of spatial spillovers from a municipality $j$ for every sector of activity $s$ (among those included in each sub-sample), that is, it can be computed $S I E_{j \mid s}$ and $D E_{j \mid s}$. However, to simplify the discussion of the results, Figure 3 presents aggregated measures of spatial effects from a municipality, computed as a weighted average of the form:

$$
S I E_{j}=\sum_{s} \frac{n_{s}}{n} S I E_{j \mid s},
$$

where $n_{s}$ represent the number of firms in the sector $s$, and $n$ is the total number of firms in the corresponding sub-sample. 